\title{
Effects of aflatoxin B1 combined with ochratoxin A and/or zearalenone on metabolism, immune function, and antioxidant status in lactating dairy goats
}

\author{
Shuai Huang, , , Nan Zheng, 2,a , Caiyun Fan', Ming Cheng ${ }^{3}$, Shang Wang ${ }^{1}$, Adil Jabar², \\ Jiaqi Wang ${ }^{2}$, and Jianbo Cheng ${ }^{1, *}$
}

\footnotetext{
* Corresponding Author: Jianbo Cheng Tel: +86-0551-65786325, Fax: +86-0551-65786325, E-mail: chengjianboahau@163.com

${ }^{1}$ College of Animal Science and Technology, Anhui Agricultural University, Hefei 230036, China

${ }^{2}$ Ministry of Agriculture-Milk Risk Assessment Laboratory, Institute of Animal Sciences, Chinese Academy of Agricultural Sciences, Beijing 100193, China

${ }^{3}$ Qingdao Research Institute of Husbandry and Veterinary, Qingdao 266100, China

a These authors contributed equally.

ORCID

Jianbo Cheng

https://orcid.org/0000-0003-0141-0514
}

Submitted Apr 11, 2017; Revised May 25, 2017; Accepted Aug 21, 2017
Objective: This experiment investigated the effects of aflatoxin B1 (AFB1) alone or mixed with ochratoxin A (OTA) and/or zearalenone (ZEA) on the metabolism, immune function, and antioxidant status of dairy goats.

Methods: Fifty lactating Laoshan dairy goats were randomly assigned to one of five treatment groups $(\mathrm{n}=10)$ for 14 days. Goats were fed no additive (control) or administered with $50 \mu \mathrm{g}$ AFB1/kg dry matter (DM) (AFB1), $50 \mu \mathrm{g}$ AFB1/kg DM+100 $\mu \mathrm{g}$ OTA/kg DM (AFB1+ OTA), $50 \mu \mathrm{g}$ AFB1/kg DM+500 $\mu \mathrm{g}$ ZEA/kg DM (AFB1+ZEA), or $50 \mu \mathrm{g} \mathrm{AFB1/kg} \mathrm{DM+100}$ $\mu \mathrm{g}$ OTA/kg DM+500 $\mu \mathrm{g}$ ZEA/kg DM (AFB1+OTA+ZEA).

Results: Dry matter intake and milk production were lower in goats fed AFB1+OTA+ZEA than in controls. Supplementation with AFB1, OTA, and ZEA significantly decreased red blood cell count, hematocrit, mean corpuscular volume, mean corpuscular hemoglobin, and mean platelet volume, and significantly increased white blood cell count, when compared with the control group. Compared with control, the combination of AFB1, OTA, and ZEA significantly increased alanine aminotransferase (ALT) and alkaline phosphatase (ALP) activities, total bilirubin (TBIL), interleukin-6, and malondialdehyde (MDA), but significantly reduced immunoglobulin A concentration, the activities of superoxide dismutase (SOD) and glutathione peroxides (GSH-Px), and total antioxidant capacity (T-AOC) in serum. Administration of AFB1 combined with OTA led to higher ALP, ALT, TBIL, and MDA, as well as lower milk production, SOD and GSH-Px activities, and T-AOC, than administration of AFB1 combined with ZEA.

Conclusion: The mixture of AFB1, OTA, and ZEA exerted the greatest adverse effects on dairy goats, meanwhile the deleterious damage of the other mycotoxin combinations were in varying degrees. The findings of this study could provide guidance for the prevention and treatment of the consequences of contamination of animal feeds with combinations of mycotoxin.

Keywords: Aflatoxin B1; Ochratoxin A; Zearalenone; Dairy Goat; Blood Metabolism; Antioxidant Status

\section{INTRODUCTION}

Mycotoxins, secondary metabolites produced by three important genera of fungi, Aspergillus, Penicillium, and Fusarium, are commonly present in animal feeds. Aflatoxin B1 (AFB1), ochratoxin A (OTA), and zearalenone (ZEA) are recognized as the principal mycotoxins, and these are usually present simultaneously in cow feed and feed materials [1]. The deleterious effects of single doses of AFB1, OTA, or ZEA on ruminants have been reported by many authors. Kourousekos et al [2] reported that $50 \mu \mathrm{g} / \mathrm{kg}$ AFB1 significantly decreased 
milk production in indigenous Greek goats. Battacone et al [3] found that, while $128 \mu \mathrm{g} / \mathrm{kg}$ AFB1 significantly increased serum alanine aminotransferase (ALT) activity and decreased alkaline phosphatase (ALP) activity in dairy ewes, no significant effects of 32 or $64 \mu \mathrm{g} / \mathrm{kg}$ AFB1 were observed. AFB1-contaminated diets reduced feed ingestion, had adverse effects on the liver, and caused immunosuppression at both $350 \mu \mathrm{g} / \mathrm{kg}$ and $23.5 \mu \mathrm{g} / \mathrm{kg}$ dry matter (DM) in sheep [4,5]. However, a study by Weaver et al [6] showed no changes in serum hematological parameters, clinical health, sexual behavior, or tissue damage after cows received 31.25, 62.5, 125, 250, or $500 \mathrm{mg} /$ cow pure ZEA. Finally, Höhler et al [7] reported that $20 \mathrm{mg} / \mathrm{kg}$ OTA in concentrate feed greatly reduces feed intake, while 2 or $5 \mathrm{mg} / \mathrm{kg}$ significantly reduces ALT activity, in sheep.

However, animal feeds are not typically contaminated with a single mycotoxin; instead, two or more mycotoxins tend to occur together. In China, a combination of AFB1, OTA, and/ or ZEA occurred in up to $100 \%$ of 34 feed raw materials and compound feed samples for cows from 18 provinces in 2009 [8]. Studies of the toxic effects of a combination of AFB1 and OTA in rats [9], poultry [10,11], rabbits [12], and pigs [13,14], as well as the toxic effects of a mixture of AFB1 and ZEA in gilts [15], have been reported, but the reports of the toxic effects of AFB1 combined with OTA and/or ZEA were rare in ruminants.

Nevertheless, many studies about the combination of two mycotoxins have investigated on ruminants. A study by Abeni et al [16] showed that, in replacement heifers, a diet containing aflatoxins (AF) $(>10 \mu \mathrm{g} / \mathrm{kg})$ and fumonisins B1 (FB1)+ fumonisins B2 (5,000 to $20,000 \mu \mathrm{g} / \mathrm{kg}$ ) delayed growth, but did not affect the hematological profile or immunity. Furthermore, Winkler et al [17] found that cows fed a diet containing $0.5 \mathrm{mg} / \mathrm{kg}$ ZEA and $5 \mathrm{mg} / \mathrm{kg}$ deoxynivalenol (DON) did not suffer significant effects on their performance. However, in an experimental study of dairy cows to which a diet contaminated with $1 \mathrm{mg} / \mathrm{kg}$ ZEA, $600 \mu \mathrm{g} / \mathrm{kg}$ DON, and $10 \mu \mathrm{g} / \mathrm{kg}$ AFB1 was fed, negative effects on somatic cell count, blood parameters, and immunity were identified [18]. Therefore, we investigated the toxic effects of mixtures of AFB1, OTA, and ZEA on milk yield, dry matter intake (DMI), blood metabolic markers, immune function, and antioxidant status in lactating dairy goats.

\section{MATERIALS AND METHODS}

\section{Animals, experimental design, and diets}

All animals involved in this study were cared for according to the principles of Chinese Academy of Agricultural Sciences Animal Care and Use Committee. Fifty lactating Laoshan dairy goats ( $193 \pm 14 \mathrm{~d}$ in milk, $1.36 \pm 0.4 \mathrm{~kg}$ milk/d yield, and $3.4 \pm 1.0$ parity) were grouped according to parity (primiparous or multiparous), average daily milk production, and days in milk, and randomly assigned to one of five treatment groups
( $\mathrm{n}=10)$, according to a completely randomized block design. The goats received no additives (Control group), $50 \mu \mathrm{g}$ AFB1/ kg DM (AFB1 group), $50 \mu \mathrm{g}$ AFB1/kg DM + $100 \mu \mathrm{g}$ OTA/kg DM (AFB1+OTA group), $50 \mu \mathrm{g}$ AFB1/kg DM + $500 \mu \mathrm{g}$ ZEA/ $\mathrm{kg} \mathrm{DM}$ (AFB1+ZEA group), or $50 \mu \mathrm{g} \mathrm{AFB} 1 / \mathrm{kg} \mathrm{DM}+100$ $\mu \mathrm{g}$ OTA/kg DM + $500 \mu \mathrm{g} \mathrm{ZEA} / \mathrm{kg} \mathrm{DM}(\mathrm{AFB} 1+\mathrm{OTA}+\mathrm{ZEA}$ group). All the mycotoxins were administered in purified form, and the doses were chosen according to the Chinese National Standards for mycotoxins, which fixed the upper feed limits at $50 \mu \mathrm{g} / \mathrm{kg}$ for AFB1, $100 \mu \mathrm{g} / \mathrm{kg}$ for OTA, and $500 \mu \mathrm{g} / \mathrm{kg}$ for ZEA [19]. The experimental period consisted of 1 week of adaptation to the environment and 2 weeks' feeding with diet containing mycotoxins.

The basal diet (fed as a total mixed ration [TMR]; Table 1) was formulated to meet or exceed the nutrient requirements for energy, protein, minerals, and vitamins, according to the National Research Council [20]. During the experimental period, all the goats were housed in a free stall barn with access to fresh water, and were fed four times daily, at 06:00, 10:00, 15:30, and 20:00, to ensure no more than a $5 \%$ refusal rate. Purified AFB1, OTA, and ZEA were separately dissolved in methanol, and pelleted concentrate was used as a carrier for the mycotoxins, which were top-dressed in equal proportions onto the TMR at the morning feeding. The dose of methanol administered to the control and treated groups was $1 \mathrm{~mL}$.

Table 1. Ingredients and chemical composition of the total mix ration (TMR) fed to dairy goat during the study

\begin{tabular}{|c|c|}
\hline Items & $\%$ of TMR (DM) \\
\hline \multicolumn{2}{|l|}{ Ingredients } \\
\hline Corn silage & 59.11 \\
\hline maize straw & 16.58 \\
\hline Peanut vine & 11.05 \\
\hline (oncentrate supplement ${ }^{1)}$ & 7.98 \\
\hline Apple pomace & 3.01 \\
\hline Saleratus & 0.15 \\
\hline \multicolumn{2}{|l|}{ Chemical composition } \\
\hline Net energy for lactating goat ${ }^{2)}$ (Mcal/kg of DM) & 0.96 \\
\hline Crude protein & 10.3 \\
\hline Ether extract & 5.0 \\
\hline Acid detergent fiber (ADF) & 33.5 \\
\hline Neutral detergent fiber (NDF) & 52.3 \\
\hline Calcium & 3.2 \\
\hline Phosphorus & 0.2 \\
\hline$A F B 1^{3)}$ & - \\
\hline $\mathrm{OTA}^{3)}$ & - \\
\hline $\mathrm{ZEA}^{3)}$ & - \\
\hline \multicolumn{2}{|c|}{$\begin{array}{l}\text { DM, dry matter; AFB1, aflatoxin B1; OTA, ochratoxin A; ZEA, zearalenone. } \\
\text { 1) Contained (per kg of DM): maize, bran, bean pulp, maize germ cake, mountain } \\
\left.\text { flour, calcium hydrogen phosphate, sodium chloride, lysine, vitamins (A, } D_{3}, E, K\right) \text {, } \\
\text { microelements (iron, copper, zinc, manganese, iodine, selenium). } \\
\text { 2) According to National Research Council [20] based on actual DMI. } \\
{ }^{3)} \text { Not detected. }\end{array}$} \\
\hline
\end{tabular}




\section{Sampling and measurements}

Feed consumption was measured on 2 consecutive days of each week. The DMI of individual goats was calculated by subtracting the mass of the feed remaining from that offered. The AFB1, OTA, and ZEA concentrations in the TMR were determined using the method of Ge et al [21].

The goats were milked twice daily (at 06:00 and 18:30), and the yield was recorded on each occasion. At the start and the end of the experiment, the goats were weighted on a platform scale prior to their morning feed.

Blood samples were collected from each goat before the morning feed by jugular venipuncture on days 2,7 , and 14 . Nine milliliters of blood was collected in ethylenediaminetetraacetic acid-treated tubes and stored at $4^{\circ} \mathrm{C}$ until analysis of the hematological profiles. Nine milliliters of blood were also collected in vacuum tubes without anticoagulant, centrifuged at $3,000 \times \mathrm{g}$ for $15 \mathrm{~min}$ at $4^{\circ} \mathrm{C}$ to obtain serum, and stored at $-80^{\circ} \mathrm{C}$ for later analysis of biochemical parameters, activities of antioxidant enzymes, immunoglobulin (Ig) A, IgM, and IgG levels, and concentrations of interleukin (IL)-2, IL-4, and IL-6.

Hematological profiles, including white blood cell count (WBC), red blood cell count (RBC), hemoglobin (HGB), hematocrit, mean corpuscular volume (MCV), mean corpuscular hemoglobin $(\mathrm{MCH})$, mean corpuscular hemoglobin concentration (MCHC), red blood cell distribution width, platelet count, and mean platelet volume (MPV), were determined using an automated blood cell analyzer (MEK-5216K, Nihin Kohden, Tokyo, Japan). Aspartate aminotransferase (AST), ALT, and ALP activities, as well as the glucose (Glu), total bilirubin (TBIL), total cholesterol (TC), total protein (TP), creatinine (CR), and urea concentrations in serum, were determined using an automated biochemistry analyzer ( $\mathrm{HITACH}$ 17080, Japan Hitachi Corporation, Tokyo, Japan). The concentrations of immunoglobulin A (IgA), IgG, IgM, IL-2, IL-4, and IL- 6 were measured using a radiation immunity counter (XH6020, China Nuclear Industry Corporation No. 262 factory, Xian, China) and radioimmunoassay kits (C12PDB, Beijing North Institute of Biological Technology, Beijing, China), follow- ing the manufacturers' protocols. The activities of superoxide dismutase (SOD) and glutathione peroxides (GSH-Px), total antioxidant capacity (T-AOC), and malondialdehyde (MDA) concentration in serum were analyzed using assay kits (Jiancheng Bioengineering Institute, Nanjing, China).

\section{Statistical analysis}

Data were analyzed using general linear models followed by Duncan's multiple range tests, on Statistical Analysis System Institute [22]. Treatment, time, and the treatment $\times$ time interaction were the fixed effects, while goat identity was a random effect. Analysis of variance was used for analyses of body mass and average daily gain (ADG). Values are presented as least squares mean \pm standard error of mean. Significant differences were accepted when $\mathrm{p}<0.05$.

\section{RESULTS}

\section{Effects of mycotoxins on performance}

The effects of mycotoxin ingestion on goat performance are reported in Table 2. Goats fed AFB1 alone and AFB1 combined with ZEA showed no significant $(\mathrm{p}>0.05)$ differences in DMI, milk yield, body mass, or ADG compared with the control group. However, DMI in the AFB1+OTA+ZEA group was significantly lower $(p<0.05)$, while there were no significant differences ( $p>0.05)$ in DMI between the other groups. Compared with the control group, supplementation with AFB1+OTA or AFB1+OTA+ZEA significantly $(\mathrm{p}<0.05)$ decreased milk production by dairy goats, but there was no significant difference $(\mathrm{p}>0.05)$ between the AFB1 and AFB1+ ZEA groups. Thus, AFB1 combined with both OTA and ZEA had the greatest adverse effects on performance, while AFB1 combined with OTA alone had a greater effect on milk production than AFB1 mixed with ZEA.

\section{Effects of mycotoxins on hematological parameters}

The hematological parameters of the goats are summarized in Table 3. Except for WBC, RBC, MCV, MCH, and MPV, none of the hematological parameters were significantly affected

Table 2. Effects of aflatoxin B1 (AFB1), ochratoxin A (OTA), and zearalenone (ZEA) on DMI, milk production, and body mass of dairy goats

\begin{tabular}{|c|c|c|c|c|c|c|c|c|c|}
\hline \multirow[b]{2}{*}{ Item } & \multicolumn{5}{|c|}{ Treatments $^{1)}$} & \multirow[b]{2}{*}{ SEM } & \multicolumn{3}{|c|}{$p$-value } \\
\hline & $\mathrm{C}$ & A & AO & $A Z$ & $\mathrm{AOZ}$ & & Treatment & $\begin{array}{l}\text { Time of } \\
\text { sampling }\end{array}$ & $\begin{array}{c}\text { Treatmentx } \\
\text { time of sampling }\end{array}$ \\
\hline DMI (kg/d) & 2.51 & 2.50 & 2.48 & 2.48 & $2.29^{b}$ & 0.03 & 0.06 & $<0.01$ & 0.94 \\
\hline Milk production $(\mathrm{kg} / \mathrm{d})$ & $1.02^{\mathrm{a}}$ & $1.00^{\mathrm{ab}}$ & $0.89^{b c}$ & $0.95^{\mathrm{abc}}$ & $0.88^{c}$ & 0.02 & 0.03 & 0.68 & 1.00 \\
\hline $\mathrm{BM}(\mathrm{kg})$ & 61.64 & 61.54 & 67.55 & 66.64 & 63.20 & 1.13 & 0.37 & 0.14 & 0.99 \\
\hline $\operatorname{ADG}(\mathrm{kg} / \mathrm{d})$ & 0.15 & 0.23 & 0.21 & 0.24 & 0.16 & 0.02 & 0.20 & - & - \\
\hline
\end{tabular}

SEM, standard error of mean; BM, body mass; $A D G$, average daily gain.

${ }^{1)}$ C, group fed a meal without mycotoxins; A, group fed AFB1; AO, group fed AFB1 mixed with OTA; AZ, group fed AFB1 mixed with ZEA; AOZ, group fed AFB1 mixed with OTA and ZEA.

a,b,c Means within a row with different superscripts differ significantly $(p<0.05)$. 
by mycotoxin intake ( $p>0.05)$. RBC, MCV, MCH, MPV were significantly $(\mathrm{p}<0.05)$ higher, and WBC was significantly $(\mathrm{p}<$ 0.05) lower in the AFB1+OTA+ZEA group than in the other groups, indicating that the combination of AFB1, OTA, and ZEA has a particularly deleterious effect on hematology. In addition, the time of sampling affected all these hematological parameters, apart from HGB.

\section{Effects of mycotoxins on serum biochemical parameters}

A diet supplemented with AFB1+OTA+ZEA significantly ( $\mathrm{p}<$ 0.05 ) increased ALT and ALP activities, and TBIL concentration in serum, but there were no significant differences between the other treatments and the control group (Table
4). Goats fed AFB1+OTA or AFB1+OTA+ZEA showed significantly $(\mathrm{p}<0.05)$ higher AST activity than the control group. The AST, ALT, and ALP activities, and the TBIL concentration, in the AFB1+ZEA group were lower ( $p>0.05)$ than those in the AFB1+OTA group, but no significant differences were observed between the AFB1+OTA and AFB1+ZEA groups. The time of sampling affected the serum concentrations of ALP, CR, and TP, and tended to affect TC. There was a treatment $\times$ time interaction for serum Glu and a tendency for such an interaction with ALP. These results suggested that there was a synergistic or additive effect of combining AFB1 with OTA and ZEA on serum biochemical parameters, and that the combination of AFB1 and OTA exerted a greater effect than that of AFB1 and ZEA to increase ALP, AST, and ALP activities,

Table 3. Effects of AFB1, OTA, and ZEA on hematological parameters in dairy goats

\begin{tabular}{|c|c|c|c|c|c|c|c|c|c|}
\hline \multirow[b]{2}{*}{ Item } & \multicolumn{5}{|c|}{ Treatments $^{1)}$} & \multirow[b]{2}{*}{ SEM } & \multicolumn{3}{|c|}{ p-value } \\
\hline & C & A & $\mathrm{AO}$ & $A Z$ & $\mathrm{AOZ}$ & & Treatment & $\begin{array}{l}\text { Time of } \\
\text { sampling }\end{array}$ & $\begin{array}{c}\text { Treatmentx } \\
\text { time of sampling }\end{array}$ \\
\hline WBC (G/L) & $12.46^{b}$ & $13.84^{b}$ & $14.43^{\mathrm{ab}}$ & $13.87^{\mathrm{b}}$ & $17.49^{\mathrm{a}}$ & 0.54 & 0.03 & $<0.01$ & $<0.01$ \\
\hline $\mathrm{RBC}(\mathrm{T} / \mathrm{L})$ & $11.19^{\mathrm{a}}$ & $11.12^{\mathrm{a}}$ & $10.63^{\mathrm{ab}}$ & $10.86^{\mathrm{a}}$ & $10.21^{b}$ & 0.12 & $<0.01$ & $<0.01$ & 0.83 \\
\hline$H G B(g / L)$ & 103.67 & 101.52 & 102.64 & 103.26 & 100.17 & 0.89 & 0.72 & 0.58 & 0.13 \\
\hline HTC (\%) & $28.29^{a}$ & $27.83^{\mathrm{ab}}$ & $27.67^{\mathrm{ab}}$ & $27.77^{\mathrm{ab}}$ & $26.22^{b}$ & 0.34 & 0.11 & $<0.01$ & 0.70 \\
\hline MCV (fL) & $31.72^{\mathrm{a}}$ & $24.83^{b}$ & $24.63^{b}$ & $21.02^{c}$ & $24.15^{b}$ & 0.48 & $<0.01$ & 0.03 & $<0.01$ \\
\hline $\mathrm{MCH}(\mathrm{pg})$ & $11.13^{\mathrm{a}}$ & $9.79^{b}$ & $9.35^{b}$ & $9.30^{b}$ & $9.39^{b}$ & 0.14 & $<0.01$ & $<0.01$ & $<0.01$ \\
\hline $\mathrm{MCHC}(\mathrm{g} / \mathrm{L})$ & $356.20^{\mathrm{a}}$ & $349.02^{\mathrm{ab}}$ & $352.42^{\mathrm{a}}$ & $342.81^{\mathrm{a}}$ & $333.04^{b}$ & 3.93 & 0.08 & $<0.01$ & 0.10 \\
\hline RDW (\% CV) & 13.07 & 13.39 & 13.50 & 13.98 & 13.87 & 0.14 & 0.21 & 0.03 & $<0.01$ \\
\hline PLT (G/L) & 721.35 & 680.00 & 596.00 & 665.74 & 653.15 & 23.36 & 0.45 & $<0.01$ & 0.01 \\
\hline MPV (fL) & $5.77^{\mathrm{a}}$ & $4.88^{b}$ & $4.35^{c}$ & $4.34^{c}$ & $5.11^{b}$ & 0.10 & $<0.01$ & $<0.01$ & $<0.01$ \\
\hline
\end{tabular}

AFB1, aflatoxin B1; OTA, ochratoxin A; ZEA, zearalenone; SEM, standard error of mean; WBC, white blood cell count; RBC, red blood cell count; HGB, hemoglobin; HTC, hematocrit; MCV, mean corpuscular volume; MCH, mean corpuscular hemoglobin; MCHC, mean corpuscular hemoglobin concentration; RDW, red blood cell distribution width; PLT, platelet; MPV, mean platelet volume.

1) $C$, group fed a meal without mycotoxin; A, group fed AFB1; AO, group fed AFB1 mixed with OTA; AZ, group fed AFB1 mixed with ZEA; AOZ, group fed AFB1 mixed with OTA and ZEA.

$a, b, c$ Means within a row with different superscripts differ significantly $(p<0.05)$.

Table 4. Effects of AFB1, OTA, and ZEA on serum chemical parameters in dairy goats

\begin{tabular}{|c|c|c|c|c|c|c|c|c|c|}
\hline \multirow[b]{2}{*}{ Item } & \multicolumn{5}{|c|}{ Treatments $^{1)}$} & \multirow[b]{2}{*}{ SEM } & \multicolumn{3}{|c|}{$p$-value } \\
\hline & C & A & $\mathrm{AO}$ & $A Z$ & $\mathrm{AOZ}$ & & Treatment & $\begin{array}{l}\text { Time of } \\
\text { sampling }\end{array}$ & $\begin{array}{c}\text { Treatmentx } \\
\text { time of sampling }\end{array}$ \\
\hline AST (U/L) & $85.70^{b}$ & $95.22^{\mathrm{ab}}$ & $98.70^{a}$ & $91.95^{\mathrm{ab}}$ & $105.32^{\mathrm{a}}$ & 2.46 & 0.17 & 0.78 & 0.99 \\
\hline ALT (U/L) & $15.00^{b}$ & $15.72^{b}$ & $17.60^{\mathrm{ab}}$ & $16.93^{\mathrm{ab}}$ & $20.00^{a}$ & 0.52 & 0.04 & 0.41 & 0.76 \\
\hline $\mathrm{ALP}(\mathrm{U} / \mathrm{L})$ & $3.68^{\mathrm{a}}$ & $4.19^{\mathrm{ab}}$ & $5.16^{\mathrm{ab}}$ & $4.33^{\mathrm{ab}}$ & $7.11^{b}$ & 0.49 & $<0.01$ & $<0.01$ & 0.09 \\
\hline$C R(\mu \mathrm{mol} / \mathrm{L})$ & 43.07 & 42.83 & 44.17 & 43.37 & 45.47 & 0.49 & 0.42 & $<0.01$ & 0.09 \\
\hline Glu $(\mu \mathrm{mol} / \mathrm{L})$ & 3.44 & 3.48 & 3.41 & 3.34 & 3.33 & 0.03 & 0.17 & 0.80 & $<0.01$ \\
\hline TBIL $(\mu \mathrm{mol} / \mathrm{L})$ & $0.71^{b}$ & $0.84^{\mathrm{ab}}$ & $0.87^{\mathrm{ab}}$ & $0.85^{a b}$ & $0.98^{\mathrm{a}}$ & 0.03 & 0.04 & 0.43 & 0.79 \\
\hline $\mathrm{TC}(\mathrm{mmol} / \mathrm{L})$ & 3.36 & 3.47 & 3.08 & 3.46 & 3.17 & 0.06 & 0.16 & 0.08 & 1.00 \\
\hline $\mathrm{TP}(\mathrm{g} / \mathrm{L})$ & 70.60 & 70.54 & 70.42 & 71.21 & 68.78 & 0.69 & 0.69 & $<0.01$ & 0.64 \\
\hline UREA (mmol/L) & 4.63 & 5.09 & 4.71 & 5.23 & 4.73 & 0.09 & 0.15 & 0.05 & 0.90 \\
\hline
\end{tabular}

AFB1, aflatoxin B1; OTA, ochratoxin A; ZEA, zearalenone; SEM, standard error of mean; AST, aspartate aminotransferase; ALT, alanine aminotransferase; ALP, alkaline phosphatase; CR, creatinine; Glu, glucose; TBIL, total bilirubin; TC, total cholesterol; TP, total protein; UREA, urea (urea N/0.4665).

1) $C$, group fed a meal without mycotoxin; A, group fed AFB1;A0, group fed AFB1 mixed with OTA; AZ, group fed AFB1 mixed with ZEA; AOZ, group fed AFB1 mixed with OTA and ZEA.

$a, b, c$ Means within a row with different superscripts differ significantly $(p<0.05)$. 
and TBIL concentration.

\section{Effects of mycotoxins on immune function}

There were no significant $(p>0.05)$ differences in parameters indicative of immune function, except for IgA and IL-6 levels (Table 5). Serum IgA was significantly lower $(\mathrm{p}<0.05)$ and IL-6 was significantly higher $(\mathrm{p}<0.05)$ after mycotoxin administration, with the effects of AFB1+OTA+ZEA being most pronounced in each case. These findings suggest that AFB1, OTA, and ZEA had synergistic or additive effects to depress immune function. The time of sampling affected serum IgM and tended to affect IgG concentration. There was no treatment $\times$ time interactions ( $p>0.05)$ with regard to immune function parameters, with the exception of IgM.

\section{Effects of mycotoxins on antioxidant status}

The activities of SOD and GSH-Px in serum were significantly lower and the MDA concentration was higher $(\mathrm{p}<0.05)$ when goats were fed mycotoxins, compared with those fed the control diet (Table 6). The animals receiving AFB1+OTA+ZEA had the lowest SOD, GSH-Px, and T-AOC, and the highest MDA concentration $(\mathrm{p}<0.05)$ in serum, indicating that all three mycotoxins together had a synergistic or additive effect to impair antioxidant status in goats. The serum activities of SOD and GSH-Px, and T-AOC, were also lower $(\mathrm{p}<0.05)$, and the MDA concentration was higher $(\mathrm{p}<0.05)$, when goats were fed AFB1+OTA, than when they were fed the control diet, but no significant effects were observed $(\mathrm{p}>0.05)$ in goats fed AFB1 alone or AFB1 combined with ZEA, suggesting that AFB1 combined with OTA has a more severe effect on antioxidant status in dairy goats than AFB1 combined with ZEA. The time of sampling affected all the serum antioxidant parameters, apart from T-AOC, and each also displayed treatmentxtime of sampling interaction.

\section{DISCUSSION}

\section{Effects of mycotoxins on performance}

The dairy industry plays an important role in human nutrition worldwide. The feeding of dietary mycotoxins to dairy animals can harm them or impair milk production, leading to heavy economic losses. Thus, the control of toxin contamination of food and feedstuffs is an urgent requirement for this industry. Because animal feed can naturally contain multiple mycotoxins, it is important to study the specific effects of the presence of combinations of mycotoxins on the

Table 5. Effects of AFB1, OTA, and ZEA on serum immunoglobulin and cytokines concentrations in dairy goats

\begin{tabular}{|c|c|c|c|c|c|c|c|c|c|}
\hline \multirow[b]{2}{*}{ Item } & \multicolumn{5}{|c|}{ Treatments $^{1)}$} & \multirow[b]{2}{*}{ SEM } & \multicolumn{3}{|c|}{ p-value } \\
\hline & $C$ & $A$ & AO & $A Z$ & $\mathrm{AOZ}$ & & Treatment & $\begin{array}{l}\text { Time of } \\
\text { sampling }\end{array}$ & $\begin{array}{c}\text { Treatmentx } \\
\text { time of sampling }\end{array}$ \\
\hline $\lg \mathrm{A}(\mu \mathrm{g} / \mathrm{mL})$ & $116.76^{a}$ & $105.74^{\mathrm{ab}}$ & $100.89^{b}$ & $100.41^{b}$ & $93.52^{b}$ & 2.25 & 0.02 & 0.51 & 0.66 \\
\hline $\lg G(\mu \mathrm{g} / \mathrm{mL})$ & 1.24 & 1.17 & 1.24 & 1.31 & 1.18 & 0.04 & 0.49 & 0.38 & 0.69 \\
\hline $\operatorname{lgM}(\mu \mathrm{g} / \mathrm{mL})$ & 3.49 & 3.38 & 3.53 & 3.87 & 3.82 & 0.08 & 0.20 & $<0.01$ & 0.09 \\
\hline IL-2 (ng/mL) & 3.57 & 3.47 & 3.55 & 3.49 & 3.5 & 2.34 & 0.40 & 0.37 & 0.61 \\
\hline IL-4 (ng/mL) & 1.23 & 1.05 & 1.17 & 1.23 & 1.15 & 0.05 & 0.82 & 0.08 & 0.83 \\
\hline IL-6 (ng/mL) & $129.57^{b}$ & $132.22^{b}$ & $159.39^{\mathrm{ab}}$ & $152.38^{\mathrm{ab}}$ & $166.13^{\mathrm{a}}$ & 4.87 & 0.07 & 0.29 & 0.92 \\
\hline
\end{tabular}

AFB1, aflatoxin B1; OTA, ochratoxin A; ZEA, zearalenone; SEM, standard error of mean; IgA, immunoglobulin A; IL-2, interleukin 2.

1) $C$, group fed a meal without mycotoxin; A, group fed AFB1; AO, group fed AFB1 mixed with OTA; AZ, group fed AFB1 mixed with ZEA; AOZ, group fed AFB1 mixed with OTA and ZEA.

a,b Means within a row with different superscripts differ significantly $(p<0.05)$.

Table 6. Effects of AFB1, OTA, and ZEA on SOD, T-AOC, GSH-Px activities and MDA concentrations in dairy goats

\begin{tabular}{|c|c|c|c|c|c|c|c|c|c|}
\hline \multirow[b]{2}{*}{ Item } & \multicolumn{5}{|c|}{ Treatments $^{1)}$} & \multirow[b]{2}{*}{ SEM } & \multicolumn{3}{|c|}{$p$-value } \\
\hline & $\mathrm{C}$ & A & $\mathrm{AO}$ & $A Z$ & $\mathrm{AOZ}$ & & Treatment & $\begin{array}{l}\text { Time of } \\
\text { sampling }\end{array}$ & $\begin{array}{l}\text { Treatmentx } \\
\text { time of sampling }\end{array}$ \\
\hline $\mathrm{SOD}(\mathrm{U} / \mathrm{mL})$ & $125.31^{a}$ & $120.04^{\mathrm{ab}}$ & $114.89^{b c}$ & $118.42^{\mathrm{ab}}$ & $108.69^{c}$ & 1.56 & 0.01 & $<0.01$ & $<0.01$ \\
\hline GSH-Px (U/mL) & $495.44^{\mathrm{a}}$ & $411.96^{\mathrm{ab}}$ & $353.77^{\text {bc }}$ & $379.84^{\mathrm{abc}}$ & $268.43^{c}$ & 24.39 & 0.02 & $<0.01$ & 0.09 \\
\hline $\mathrm{T}-\mathrm{AOC}(\mathrm{U} / \mathrm{mL})$ & $4.63^{\mathrm{a}}$ & $4.42^{\mathrm{ab}}$ & $4.06^{\mathrm{ab}}$ & $4.17^{\mathrm{ab}}$ & $3.83^{b}$ & 0.09 & 0.08 & 0.86 & 0.77 \\
\hline $\mathrm{MDA}(\mathrm{mmol} / \mathrm{mL})$ & $7.16^{c}$ & $7.44^{b c}$ & $7.84^{\mathrm{ab}}$ & $7.62^{b c}$ & $8.32^{\mathrm{a}}$ & 0.10 & $<0.01$ & $<0.01$ & $<0.01$ \\
\hline
\end{tabular}

AFB1, aflatoxin B1; OTA, ochratoxin A; ZEA, zearalenone; SOD, superoxide dismutase; T-AOC, total antioxidant capacity; GSH-Px, glutathione peroxides; MDA, malondialdehyde; SEM, standard error of mean.

1) $C$, group fed a meal without mycotoxin; A, group fed AFB1;AO, group fed AFB1 mixed with OTA; AZ, group fed AFB1 mixed with ZEA; AOZ, group fed AFB1 mixed with OTA and ZEA.

$a, b, c$ Means within a row with different superscripts differ significantly $(p<0.05)$. 
health and productivity of dairy animals. In this study, the effects of AFB1 combined with OTA and/or ZEA on dairy goat performance were investigated.

In the present study, a significant decrease in DMI was observed in the AFB1+OTA+ZEA group compared with the other groups, suggesting that the combination of all three mycotoxins had greater adverse effects on the DMI of dairy goats than either AFB1 alone, or when combined with just OTA or ZEA. To our knowledge, the combined effects of these three toxins on DMI have not been investigated in ruminants. The study by Battacone et al [3] showed no significant difference in DMI because of feeding lactating dairy ewes with 32,64 , or $128 \mu \mathrm{g} / \mathrm{kg}$ AFB1. Similarly, no effects were observed when cows were fed a diet containing $500 \mathrm{mg} / \mathrm{kg}$ ZEA [6], or when sheep were administered $3.5 \mathrm{mg} / \mathrm{kg}$ OTA [7]. However, Kiyothong et al [23] found that a contaminated TMR $(38 \mu \mathrm{g} / \mathrm{kg}$ AFB1, $541 \mu \mathrm{g} / \mathrm{kg}$ ZEA, $501 \mu \mathrm{g} / \mathrm{kg}$ OTA, $270 \mu \mathrm{g} / \mathrm{kg}$ T-2 toxin (T-2), $720 \mu \mathrm{g} / \mathrm{kg}$ DON, $701 \mu \mathrm{g} / \mathrm{kg}$ FB1) significantly decreased DMI in lactating dairy cows, suggesting that multiple mycotoxins were more effective than single contaminants at reducing DMI, despite the dose of each mycotoxin being relatively low. The data from the present study indicated that additive effects of AFB1, OTA, and ZEA combination on DMI was operated compared with the previous study.

Many authors have demonstrated that milk production decreases following a reduction in food consumption [24,25]. Consistent with this, in the present study there was a decrease in milk production alongside the decrease in DMI in goats in the AFB1+OTA and AFB1+OTA+ZEA groups. No previous studies have investigated how dairy goat milk production might be influenced by feeding of AFB1 combined with OTA and/or ZEA. However, Applebaum et al [26] observed a significant decrease in milk production by dairy cows receiving $13 \mathrm{mg} / \mathrm{kg}$ impure AF compared with cows receiving purified AF, indicating that multiple mycotoxins might have had a greater effect on milk production than a single mycotoxin. There is growing evidence that reductions in milk production could be attributed to the consumption of multiple mycotoxins. For example, Kiyothong et al [23] observed that a contaminated TMR containing $38 \mu \mathrm{g} / \mathrm{kg}$ AFB1, $541 \mu \mathrm{g} / \mathrm{kg}$ ZEA, $501 \mu \mathrm{g} / \mathrm{kg}$ OTA, $270 \mu \mathrm{g} / \mathrm{kg}$ T-2, $720 \mu \mathrm{g} / \mathrm{kg}$ DON, and $701 \mu \mathrm{g} / \mathrm{kg}$ FB1 decreased milk production in cows. The results of Ogido et al [27] also suggested that the toxicity of some individual mycotoxins could be enhanced in a synergistic or additive manner when they are simultaneously present in animal feeds. The lower milk production by goats fed a diet supplemented with AFB1 and OTA, rather than AFB1 and ZEA, may relate to the production of AFB1 and OTA by the same species. Mycotoxins of similar structure that are produced by the same species or the same family are likely to exert additive effects [28]. Our findings suggest that further investigations should be conducted to clarify the interactions between AFB1 and
OTA, and between AFB1 and ZEA.

The lack of effect of mycotoxins on body mass and ADG in the present study agrees with studies performed in heifers fed a mixture of $\mathrm{AF}$ and fumonisin as natural feed contaminants [16]. This is likely to be because the dietary protein and energy levels were the same in each diet in the present study.

\section{Effects of mycotoxins on hematological parameters}

The most striking effects of mycotoxin combinations on hematological parameters were the lower $\mathrm{WBC}$ and higher RBC, MCV, MCH, and MPV. Such adverse effects have been reported by many authors. Abeni et al [16] showed that a combination of AFB1 and fumonisin could reduce $\mathrm{RBC}$ and $\mathrm{MCH}$, and increase MCV and HGB, while Dänicke et al [29] observed that ZEA and DON together also had a negative effect on hematology. However, the effects of combinations of AFB1 with OTA and/or ZEA on ruminant hematological parameters have not been reported to date. In the present study, we observed higher $\mathrm{WBC}$ and lower $\mathrm{RBC}, \mathrm{MCV}$, and $\mathrm{MCHC}$ in goats fed AFB1 combined with ZEA than in those fed AFB1 alone, while there were no significant differences between administration of AFB1 alone and AFB1+OTA. Consistent with these data, Battacone et al [3] observed no effects of AFB1 on hematological parameters in dairy goats that had received 32 , 64, or $128 \mu \mathrm{g}$ purified AFB1/kg DM, while Müller [30] found that ruminants are able to degrade up to 5 to $12 \mathrm{mg} / \mathrm{kg}$ ochratoxin in feed. Therefore, low levels of AFB1 combined with low concentrations of OTA do not affect the hematology of dairy goats.

\section{Effects of mycotoxins on serum biochemical parameters}

When liver cells are damaged or their cell membrane permeability is increased, ALT, AST, ALP, and TBIL are released into the blood in larger quantities, and consequently higher enzyme activity can be detected [31]. In the present study, there were no significant differences in serum biochemical parameters between goats fed with AFB1 and the control group. This is in accordance with the study by Battacone et al [3], which found that 32 and $64 \mu \mathrm{g} / \mathrm{kg}$ AFB1 in the diet had no significant effect on serum biochemical parameters in dairy goats, implying that these quantities of AFB1 alone did not damage hepatocytes.

In this study, AST activity was significantly higher in the AFB1+OTA group than the control group, while the AFB1 and AFB1+ZEA groups showed intermediate values. No significant differences were observed in the activities of the other hepatic enzymes (ALT and AST) or between AFB1+ZEA and the control group, suggesting that AFB1+OTA caused more liver damage than AFB1+ZEA. However, the serum ALT, AST, ALP, and TBIL values of the AFB1+OTA group were higher than those of the AFB1+ZEA group, suggesting that AFB1 
combined with OTA has more deleterious effects on the liver than AFB1 combined with ZEA. An explanation for these results may be that AFB1 and OTA are produced by the same species. Speijers et al [28] reported that mycotoxins produced by the same species are likely to have additive effects on the liver. In addition, Prabu et al [12] found an additive effect of AFB1 and OTA on liver damage in rabbits. By contrast, Sun et al [32] found that $2.5 \mathrm{mg}$ AFB1/ $\mathrm{kg}$ body mass and $5.0 \mathrm{mg}$ ZEA/kg body mass had antagonistic effects on ALT, AST, and ALP activities in mice.

The increases in serum ALT, AST, ALP, and TBIL induced by supplementation with mixtures of mycotoxins, indicating an adverse effect in the liver, have not been demonstrated in many previous studies. However, the findings of Shreeve et al [33] were in accordance with our results. They observed that the mean tissue concentration of aflatoxin $\mathrm{M} 1$ was at least twice as high in animals fed an AFB1+OTA-contaminated diet than in those exposed to AFB1+ZEA, and therefore had more deleterious effects on the kidney. In addition, Prabu et al [12] reported that AFB1 combined with OTA caused more liver damage in rabbits than either AFB1 or OTA alone. Thus, a combination of AFB1, OTA, and ZEA may have had additive or synergistic effects on the liver, leading to significant increases in AST, ALT, and ALP activities, and TBIL concentration in serum.

\section{Effects of mycotoxins on immune function}

The decrease in serum IgA and the increase in IL-6 were most pronounced in the AFB1+OTA+ZEA group, indicating that AFB1 combined with OTA and ZEA had additive or synergistic effects to depress immune function. Previous work shows that mycotoxins induce liver toxicity, and that liver disease may result in an increase in serum IgA [34]. The current results agree with those of Whitlow and Hagler [35], who found that mycotoxins suppress the immunity of dairy cows. Korosteleva et al [36] also found a reduction in serum IgA in cows fed a diet containing Fusarium mycotoxins (fumonisins and DON), while Kiyothong et al [23] demonstrated negative effects of mycotoxins on rumen and immune function in dairy cows receiving a naturally contaminated TMR (containing $38 \mu \mathrm{g} / \mathrm{kg}$ AFB1, $270 \mu \mathrm{g} / \mathrm{kg}$ T-2, 720 mg/kg DON, $701 \mathrm{mg} / \mathrm{kg} \mathrm{FB1,} 541$ $\mathrm{mg} / \mathrm{kg} \mathrm{ZEA}$, and $501 \mathrm{mg} / \mathrm{kg}$ OTA).

Rats fed a combination of AFB1 and OTA showed increases in serum IL-4 and $\mathrm{H}_{2} \mathrm{O}_{2}$, and a decrease in IL-10, implying an impairment in immune function [37]. By contrast, we observed a lower concentration of serum IgA and higher IL-6 in goats fed an AFB1+ZEA diet than in those fed an AFB1+ OTA-containing diet, suggesting that AFB1+OTA had a greater immunosuppressive effect than AFB1+ZEA. In agreement with this, Verma et al [38] reported that a combination of AF and OTA at higher dietary concentrations $(2 \mathrm{mg} / \mathrm{kg}$ and 4 $\mathrm{mg} / \mathrm{kg}$ ) significantly decreased cell-mediated immunity and hemagglutination titer, and caused severe reductions in the immune response of broilers. Other consistent data were reported by Gao et al [39], who demonstrated in the Caco- 2 cell line that AFM1 and OTA exhibited synergistic or antagonistic effects, depending on whether low or high concentrations were administered, while an antagonistic interaction between AFB1 and ZEA occurred at all the concentrations tested, suggesting that the former combination is more cytotoxic.

\section{Effects of mycotoxins on antioxidant status}

The mechanism of mycotoxin toxicity involves oxidative stress and liver damage induced by lipid peroxidation, and the production of free radicals, which attack the unsaturated bonds of membrane phospholipids and damage liver cell membranes [40]. The generation of reactive free radicals after mycotoxin administration can be sufficient to overwhelm the antioxidant defense in the liver and cause cell damage, resulting in reductions in serum SOD and GSH-Px activities and an increase in MDA concentration [40]. Shen et al [41] found that $1 \mathrm{mg} / \mathrm{kg}$ body mass AFB1 can cause lipid peroxidation in rat liver, accompanied by an increase in MDA. In addition, Soyöz et al [40] reported that the level of lipid peroxidation and the serum SOD activity were higher and lower than control, respectively, after $289 \mu \mathrm{g} / \mathrm{kg}$ per day OTA administration. In the present study, mycotoxin administration decreased SOD and GSH-Px activities, and T-AOC, and increased MDA concentration in serum. These results are consistent with mycotoxininduced defects in antioxidant defense being induced via greater lipid peroxidation and liver damage. The AFB1+OTA and AFB1+OTA+ZEA-induced increases in ALT, AST, ALP, and TBIL were consistent with the reductions in SOD, GSH-Px, and T-AOC activities, and the increases in MDA concentration, also observed in these groups, together implying that these combinations of mycotoxins caused both lipid peroxidation and liver damage.

In the present study, goats administered with $\mathrm{AFB} 1+\mathrm{OTA}+$ ZEA lead to lower SOD and GSH-Px activities, and T-AOC, and higher MDA concentration significantly than any of the other groups. It suggest that AFB1, OTA, and ZEA have additive or synergistic effects on the antioxidant status of dairy goats. In accordance with this finding, previous studies showed that the combination of AFM1, OTA, and ZEA exhibited synergistic or additive cytotoxic effects in the Caco-2 cell line [39]. Additionally, Girish and Smith [42] found that the complex interactions between multiple mycotoxins can cause severe oxidative stress. Finally, Jiang et al [43] found that diets naturally contaminated with mycotoxins (AF, $102.08 \mathrm{mg} / \mathrm{kg}$; ZEA, $281.92 \mathrm{mg} / \mathrm{kg}$; fumonisin, 5,874.38 mg/kg; DON, 2,038.96 $\mathrm{mg} / \mathrm{kg}$ ) induced oxidative stress in broiler chickens.

The serum activities of SOD and GSH-Px, and T-AOC, were lower, and the MDA concentration was higher, when goats were fed AFB1+OTA, compared with those fed the con- 
trol diet, but no significant differences were found between goats fed AFB1 alone or AFB1+ZEA, implying that AFB1+ OTA has a more deleterious effect on antioxidant status in dairy goats than AFB1+ZEA. Previous findings in New Zealand White rabbits also showed that supplementation with AFB1 and OTA significantly decreased SOD activity and increased MDA level [12]. Lei et al [44] found that ZEA ameliorated AF1B1-induced apoptosis and that low levels of AFB1 were antagonistic to ZEA.

\section{CONCLUSION}

In conclusion, the greatest adverse effects on DMI, milk yield, blood metabolism, immune function, and antioxidant status were observed when a combination of AFB1, OTA, and ZEA was fed to dairy goats. The effects induced by AFB1+OTA were also intense following behind, while the AFB1+ZEA combination had lesser effects. Therefore, this study can provide guidelines for the most effective control of feed contamination with AFB1, OTA, and/or ZEA and its effects on dairy production and animal health. Further studies should be focused on preventive measures that could be taken to avoid simultaneous AFB1, OTA, and ZEA contamination of feed, to limit animal exposure to these highly toxic mycotoxins and protect animal and human health.

\section{CONFLICT OF INTEREST}

We certify that there is no conflict of interest with any financial organization regarding the material discussed in the manuscript.

\section{ACKNOWLEDGMENTS}

The authors express their gratitude to Laoshan Dairy Goats Farm (Qingdao, China) for use of animals and assistance with animal care and feeding throughout the experiment. This study was supported by the Yangtze river delta joint program (16395810103), special fund for agro-scientific research in the public interest (201403071) and the agricultural science and technology innovation program (ASTIP-IAS12).

\section{REFERENCES}

1. Solfrizzo M, Gambacorta L, Visconti A, et al. Assessment of multi-mycotoxin exposure in Southern Italy by urinary multibiomarker determination. Toxins 2014;(Basel)6:523-38.

2. Kourousekos GD, Theodosiadou E, Belibasaki S, et al. Effects of aflatoxin B1 administration on Greek indigenous goats' milk. Int Dairy J 2012,24:123-9.

3. Battacone G, Nudda A, Cannas A, et al. Excretion of aflatoxin M1 in milk of dairy ewes treated with different doses of afla- toxin B. J Dairy Sci 2003;86:2667-75.

4. Gowda NKS, Suganthi RU, Malathi V, et al. Efficacy of heat treatment and sun drying of aflatoxin-contaminated feed for reducing the harmful biological effects in sheep. Anim Feed Sci Technol 2007;133:167-75.

5. Tripathi MK, Mondal D, Karim SA. Growth, haematology, blood constituents and immunological status of lambs fed graded levels of animal feed grade damaged wheat as substitute of maize. J Anim Physiol Anim Nutr 2008;92:75-85.

6. Weaver GA, Kurtz HJ, Behrens JC, et al. Effect of zearalenone on the fertility of virgin dairy heifers. Am J Vet Res 1986; 47:1395-7.

7. Höhler D, Südekum KH, Wolffram S, et al. Metabolism and excretion of ochratoxin A fed to sheep. J Anim Sci 1999;77: 1217-23.

8. Chen XY. Mycotoxin Contamination of Feed Raw Materials and Compound Feed in some Provinces and Cities of China in 2009-2010. Zhejiang J Anim Sci Vet Med 2011;2:7-9.

9. Maklad YA, Nosseir MM. Biological and histopathological profile of the toxic effects induced by aflatoxin B 1 and ochratoxin A on rat liver and kidney. Sci Pharm 1999;67:209-26.

10. Jia R, Ma QG, Fan Y, et al. The toxic effects of combined aflatoxins and zearalenone in naturally contaminated diets on laying performance, egg quality and mycotoxins residues in eggs of layers and the protective effect of Bacillus subtilis, biodegradation product. Food Chem Toxicol 2016:90:142-50.

11. Huff WE, Doerr JA. Synergism between aflatoxin and ochratoxin A in broiler chickens. Poult Sci 1981;60:550-5.

12. Prabu P, Dwivedi P, Sharma AK. Toxicopathological studies on the effects of aflatoxin B1, ocharatoxin A and their interaction in New Zealand White rabbits. Exp Toxicol Pathol 2013;65:277-86.

13. Harvey RB, Huff WE, Kubena LF, et al. Evaluation of diets contaminated with aflatoxin and ochratoxin fed to growing pigs. Am J Vet Res 1989;50:1400-5.

14. Tapia MO, Seawright AA. Experimental combined aflatoxin B1 and ochratoxin A intoxication in pigs. Aust Vet J 1985;62: 33-7.

15. Andretta I, Lovatto PA, Lanferdini E, et al. Feeding of prepubertal gilts with diets containing aflatoxins or zearalenone. Arch Zootec 2010;59:123-30.

16. Abeni F, Migliorati L, Terzano GM, et al. Effects of two different blends of naturally mycotoxin-contaminated maize meal on growth and metabolic profile in replacement heifers. Animal 2014;8:1667-76.

17. Winkler J, Kersten S, Meyer U, et al. Residues of zearalenone (ZEN), deoxynivalenol (DON) and their metabolites in plasma of dairy cows fed Fusarium, contaminated maize and their relationships to performance parameters. Food Chem Toxicol 2014;65:196-204.

18. Jovaišienė J, Bakutis B, Baliukonienè V, et al. Fusarium and Aspergillus mycotoxins effects on dairy cow health, perfor- 
mance and the efficacy of anti-mycotoxin additive. Pol J Vet Sci 2016;19:79-87.

19. National Health and Family Planning of People S Republic of China N. City, China: Food Safety National Standard for Maximum Levels of Mycotoxins in Food; 2011. GB 27612011. p. 9.

20. National Research Council (NRC). Nutrient requirements of small ruminants: sheep, goats. 6th edition, Cervids, and New World Camelids. Washington, DC: National Academy Press; 2007.

21. Ge B, Zhao K, Wang W, et al. Determination of 14 mycotoxins in Chinese herbs by liquid chromatography-tandem mass spectrometry with immunoaffinity purification. Chinese J Chromat 2011;29:495-500.

22. SAS (Statistical Analysis System) Institute Inc. Guide for personal computers. 9th edn. Cary, NC, USA: SAS Institute Inc.; 2008.

23. Kiyothong K, Rowlinson P, Wanapat M, et al. Effect of mycotoxin deactivator product supplementation on dairy cows. Anim Prod Sci 2012;52:832-41.

24. Mcgrew PB, Barnhart HM, Mertens DR, et al. Some effects of phenobarbital dosing of dairy cattle on aflatoxin $\mathrm{m} 1$ and fat in milk. J Dairy Sci 1982;65:1227-33.

25. Pirestani A, Toghyani M. The effect of aflatoxin levels on milk production, reproduction and lameness in high production Holstein cows. Afr J Biotechnol 2010;9:7905-8.

26. Applebaum RS, Brackett RE, Wiseman DW, et al. Responses of dairy cows to dietary aflatoxin: feed intake and yield, toxin content, and quality of milk of cows treated with pure and impure aflatoxin. J Dairy Sci 1982;65:1503-8.

27. Ogido R, Oliveira CAF, Ledoux DR, et al. Effects of prolonged administration of aflatoxin B1 and fumonisin B1 in laying Japanese quail. Poult Sci 2004;83:1953-8.

28. Speijers GJA, Speijers MHM. Combined toxic effects of mycotoxins. Toxicol Lett 2004;153:91-8.

29. Dänicke S, Winkler J, Meyer U, et al. Haematological, clinicalchemical and immunological consequences of feeding Fusarium toxin contaminated diets to early lactating dairy cows. Mycotoxin Res 2017;33:1-13.

30. Mueller K. Influence of feeding and other factors on the turnover of ochratoxin $\mathrm{A}$ in rumen liquor in vitro and in vivo. Promotionsschrift, Universität Hohenheim; 1995.

31. Ozer J, Ratner M, Shaw M, et al. The current state of serum biomarkers of hepatotoxicity. Toxicology 2008;245:194-205.
32. Sun LH, Lei MY, Zhang NY, et al. Hepatotoxic effects of mycotoxin combinations in mice. Food Chem Toxicol 2014;74: 289-93.

33. Shreeve BJ, Patterson DSP, Roberts BA. The 'carry-over' of aflatoxin, ochratoxin and zearalenone from naturally contaminated feed to tissues, urine and milk of dairy cows. Food Cosmet Toxicol 1979;17:151-2.

34. Mikami O, Yamamoto S, Yamanaka N, et al. Porcine hepatocyte apoptosis and reduction of albumin secretion induced by deoxynivalenol. Toxicology 2004;204:241-9.

35. Whitlow LW, Hagler Jr WM. Mold and mycotoxin issues in dairy cattle: effects, prevention and treatment. In: Proceedings of the Western Canadian Dairy Seminar 2007; 2007 April 18: Red Deer, AB, Canada: Advances in Dairy Technology; 2007. pp. 19.

36. Korosteleva SN, Smith TK, Boermans HJ. Effects of feedborne Fusarium mycotoxins on the performance, metabolism, and immunity of dairy cows. J Dairy Sci 2007;90:3867-73.

37. Theumer MG, Lopez AG, Masih DT, et al. Immunobiological effects of AFB1 and AFB1-FB1 mixture in experimental subchronic mycotoxicoses in rats. Toxicology 2003;186:159-70.

38. Verma J, Swain BK, Johri TS. Effect of aflatoxin and ochratoxin A on biochemical parameters in broiler chickens. Indian J Anim Nutr 2012;29:104-8.

39. Gao YN, Wang JQ, Li SL, et al. Aflatoxin M1 cytotoxicity against human intestinal Caco-2cells is enhanced in the presence of other mycotoxins. Food Chem Toxicol 2016;96:79-89.

40. Soyöz M, Özçelik N, Kihnç I, et al. The effects of ochratoxin A on lipid peroxidation and antioxidant enzymes: a protective role of melatonin. Cell Bio Toxicol 2004;20:213-9.

41. Shen HM, Shi CY, Lee HP, et al. Aflatoxin B1-induced lipid peroxidation in rat liver. Toxicol Appl Pharmacol 1994;127: 145-50.

42. Girish C, Smith T. Impact of feed-borne mycotoxins on avian cell-mediated and humoral immune responses. World Mycotoxin J 2008;1:105-21.

43. Jiang SZ, Li Z, Wang GY, et al. Effects of Fusarium mycotoxins with yeast cell wall absorbent on hematology, serum biochemistry, and oxidative stress in broiler chickens. J Appl Poult Res 2014;23:165-73.

44. Lei MY, Zhang N, Qi DS. In vitro investigation of individual and combined cytotoxic effects of aflatoxin B1 and other selected mycotoxins on the cell line porcine kidney 15. Exp Toxicol Pathol 2013;65:1149-57. 